\title{
KHẢ NĂNG ÚNG DỤNG THIẾT BỊ MÁY ẢNH SỐ PHỔ THÔNG ĐẠTT TRÊN MÁY BAY KHÔNG NGƯời LÁI ĐỂ XÂY DỰNG QUY TRÌNH CÔNG NGHỆ THÀNH LẬP BẢN ĐỒ TỶ LỆ LỚN Ở VIỆT NAM
}

\author{
GS. TSKH. PHAN VĂN LỌC(1), ThS. NGUYẼ̃N TUẤN ANH(2) \\ (1)Trường Đại học Mỏ Địa chất \\ ${ }^{(2)}$ Công ty TNHH MTV Trắc địa Bản đồ
}

\section{Tóm tắt:}

Bài báo trình bày khả năng ứng dụng của hệ thống chụp ảnh hàng không từ máy bay không người lái (UAV) trong công tác thành lập bản đồ tỷ lệ lớn. Một hướng phát triển mới trong công nghệ thành lập bản đồ bằng phương pháp đo ảnh.

\section{Mở đầu}

حừ nửa đầu của thế kỷ XIX kỹ thuật chụp ảnh đã được ứng dụng trong công tác trắc địa địa hình. Các kỹ thuật này dựa trên những thành tựu của nhiều ngành khoa học kỹ thuật như toán học, kỹ thuật chụp ảnh khí động học, kỹ thuật điện tử, tin học ... với những cơ sở lý thuyết hoàn chỉnh và các hệ thống máy móc có độ chính xác cao, có hiệu suất công tác lớn, phương pháp đo đạc chụp ảnh có đầy đủ khả năng giải quyết nhiệm vụ đo vẽ bản đồ địa hình từ tỷ lệ nhỏ đến tỷ lệ lớn và cực lớn, giải quyết nhiều nhiệm vụ đo đạc phức tạp trong lĩnh vực khoa học kỹ thuật khác.
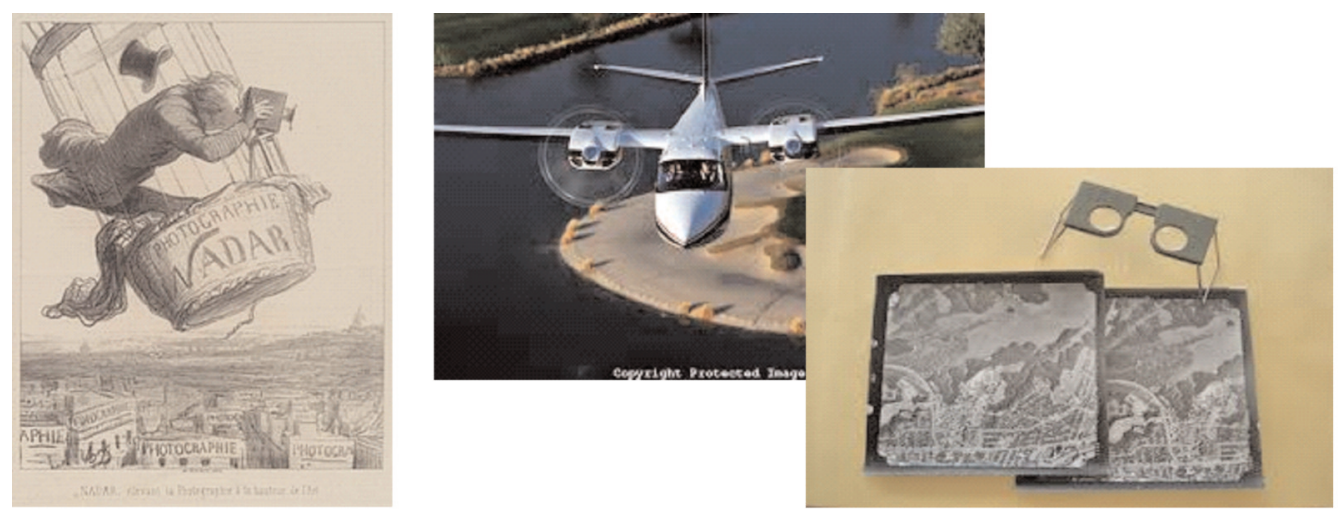

Hệ thống chụp ảnh hàng không truyền thống rất cồng kềnh, đầu tư ban đầu lớn phù hợp với công tác thành lập bản đồ tỷ lệ trung bình và bé đối với khu vực rộng lớn. Trên thế giới hệ thống máy bay không người lái được ứng dụng từ những năm 1916 chủ yếu trong lĩnh vực quân sự, cứu hộ, tình báo... Các nước tiêu biểu trong việc sử dụng công nghệ chụp ảnh hàng không từ máy bay không người lái phải kể đến hệ thống máy chụp ảnh FalconPARS của Nhật, hệ thống RCD30 và TC1235 của Thụy Sĩ và hệ thống Skate Small Unmanned Aerial System của Mỹ. Từ giữa thế kỷ $X X$ đến nay công nghệ chụp ảnh hàng không từ máy bay không người lái phát triển mạnh mẽ. Hệ thống được thiết kế nhỏ gọn, đầu tư ban đầu thấp phù hợp với công tác thành lập bản đồ tỷ lệ lớn khu vực nhỏ, thực hiện được trong môi trường khắc nghiệt, độc hại. Sử dụng hệ thống chụp ảnh hàng không từ máy bay không người lái là bước phát triển mới trong ngành chụp ảnh địa hình ở nước ta. Hướng phát triển này sẽ có ý nghĩa lớn trong tăng năng suất lao động, tăng mức độ tự 
động hóa, tăng hiệu quả kinh tế trong quy trình thành lập bản đồ tỷ lệ lớn và cực lớn. Công ty TNHH MTV Trắc địa Bản đồ đã đầu tư trang thiết bị đưa vào sử dụng hệ thống máy bay không người lái MD4-1000. Bộ Tài nguyên và Môi trường, Bộ Khoa học Công nghệ nước ta cũng đã có những khảo sát ban đầu trong lĩnh vực này.

\section{Một số hệ thống chụp ảnh hàng không từ máy bay không người lái}

Hệ thống chụp ảnh hàng không từ máy bay không người lái là sự kết hợp giữa máy chụp ảnh phổ thông được gắn trên máy bay mô hình điều khiển từ xa.
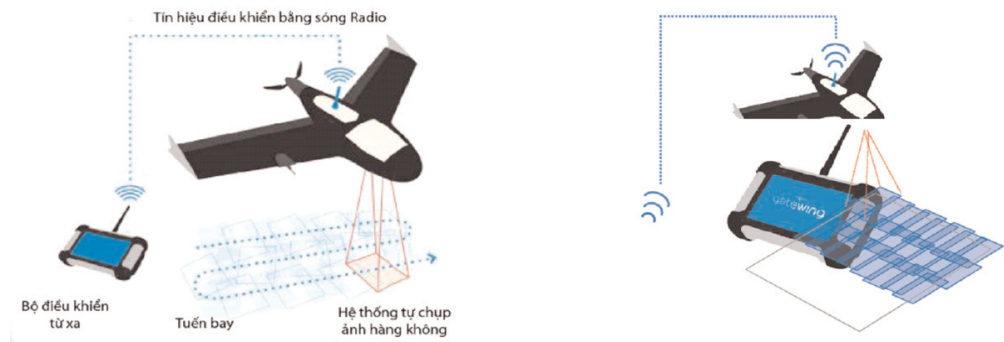

Hệ thống chụp ảnh hàng không bằng máy bay không người lái

\section{a. Giới thiệu thiết hệ thống thiết bị bay không người lái MD4-1000}

Thiết bị bay MD4-1000 là phiên bản Microdrone là loại máy bay tự hành loại nhỏ với thiết kế tinh vi (4 cánh quạt lên thẳng). Thiết bị bay MD4-1000 được thiết kế để thực hiện nhiệm vụ thăm dò, khảo sát thông tin, quan sát và kiểm tra... MD4-1000 có thể bay bằng cách kết nối với bộ điều khiển bằng sóng vô tuyến hoặc bay theo lịch trình cài sẵn nhờ sự trợ giúp của hệ thống định vị GPS dẫn đường.
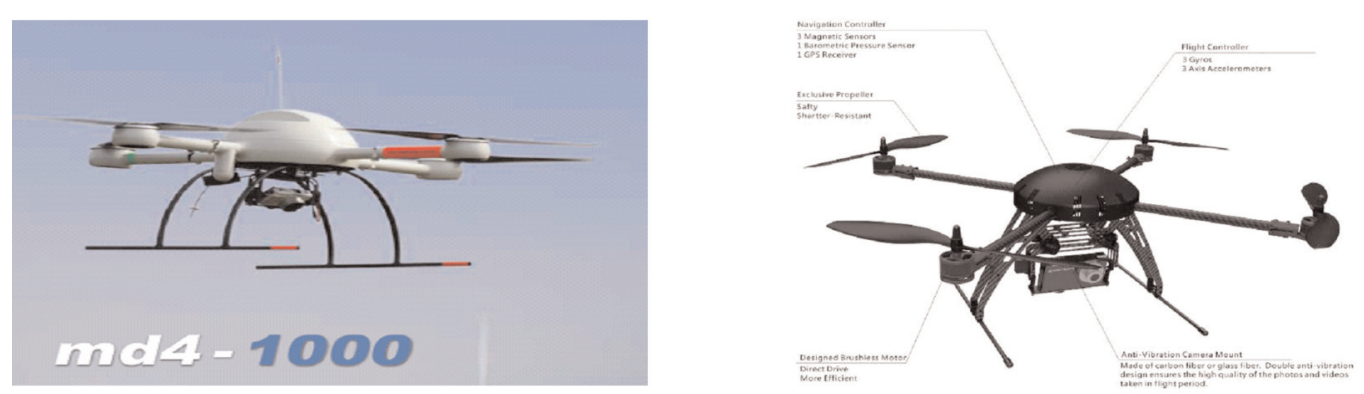

Thiết bị bay UAV nhỏ MD4-1000

Thiết bị bay MD4-1000 được thiết kế thân vỏ bằng sợi các bon, bao gồm: bộ điều khiển bay, điều khiển dẫn đường, điều khiển vào ra $\mathrm{IO}$, có bốn mô tơ cánh quạt $4 \times 250 \mathrm{~W}$ và bộ GPS/IMU, từ kế 3D, hệ thống tích hợp CAN Bus $2.0 \mathrm{~B}$ có chức năng đo khí áp, độ ẩm, vận tốc, độ cao, các góc nghiêng và hệ thống chống rung. MD4-1000 có khả năng bay tự động qua các điểm được xác định trong không gian và tương thích với thiết bị MD4-200. Thiết bị được thiết kế gập các cánh tay nên dễ dàng khi vận chuyển. So với MD4-200, MD41000 có trọng lượng nặng hơn, chịu được sức gió lớn hơn, thời gian bay kéo dài hơn và kiểm soát độ cao tốt hơn. 
Máy ảnh sử dụng cho chụp ảnh hàng không trên máy bay không người lái là máy ảnh phổ thông có tiêu cự của ống kính được khóa cố định ở một giá trị không thay đổi, không biến động khi bật hay tắt máy ảnh. Các biến dạng của hình ảnh đều được xác định chặt chẽ [1]. Các biến dạng đó mang tính hệ thống do đó có thể hiệu chỉnh và phân tích loại bỏ bởi các phần mềm chuyên dụng. Máy ảnh phải được kiểm định trước khi sử dụng vào mục đích chụp ảnh hàng không.

Trước khi tiến hành thực hiện bay chụp cần xác định độ cao bay chụp dựa vào yêu cầu về độ chính xác của nhiệm vụ cần giải quyết. Cần bay thấp hơn độ cao cho phép một khoảng nhất định. Khi độ cao bay chụp được xác định, có thể thiết kế tuyến bay bằng các phần mềm như mdCockpit hay Sử dụng module Microdrone Airborne của phần mềm OrbitGIS. Sau khi khai báo các tham số như: hệ tọa độ, máy ảnh, độ cao bay, thời gian tối đa cho 1 chuyến bay, độ phủ dọc ngang, hướng bay và vị trí cất hạ cánh..., phần mềm sẽ tự động tính toán tổng số các chuyến phải bay, số lượng ảnh chụp và bản vẽ thiết kế chi tiết các đường bay.

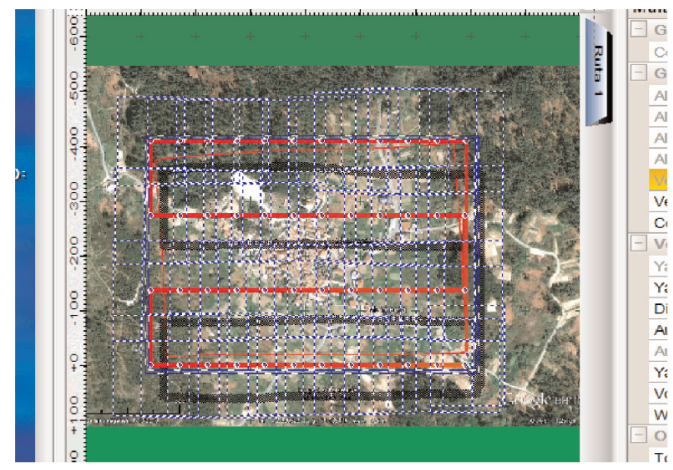

Phần mềm mdCockpit dùng để thiết kế tuyến bay

\section{b. Mộ số mô hình máy bay không người lái}

*Hệ thống UAV Falcon-PARS của Nhật

Hệ thống thu nhận hình ảnh

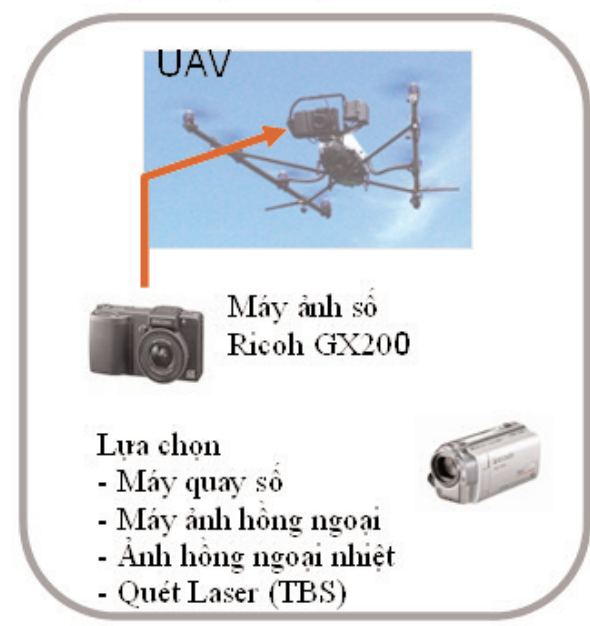

Hệ thồng xử lý dứ liệu

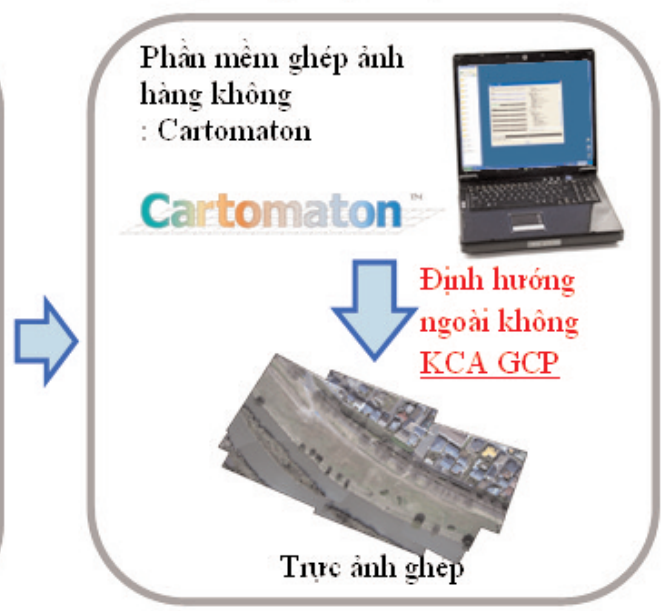


Hệ thống UAV Falcon-PARS của Nhật là thiết bị hàng không siêu nhỏ của Nhật được chế tạo theo công nghệ Đức bao gồm thiết bị bay UAV được lắp thêm máy chụp ảnh phổ thông có gắn GPS và phần mềm chuyên dụng để xử lý hình ảnh chụp.

*Hệ thống máy ảnh RCD30 và TC-1235 UAV của Thụy Sĩ

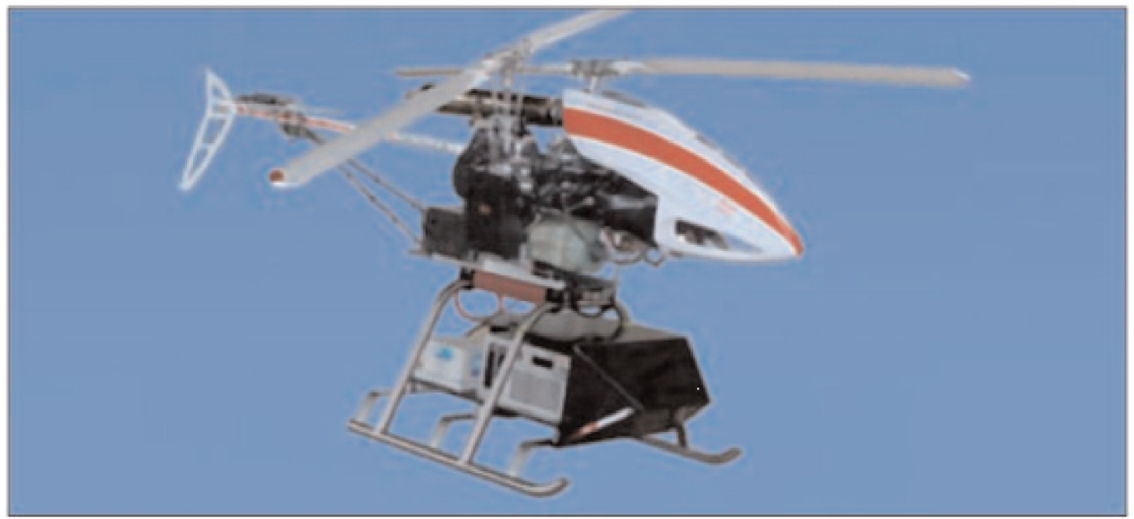

Hệ thống máy ảnh RCD30 và TC-1235UAV là sản phẩm của sự liên kết của hai hãng Leica Geosystems và Swissdrones dùng để chụp ảnh phục vụ công tác thành lập bản đồ địa hình và bản đồ $3 \mathrm{D}$.

Ngoài ra còn hệ thống Skate Small Unmanned Aerial System của Mỹ.

* Máy bay không người lái của Việt Nam.

Ngày 03/05/2013, Viện Công nghệ không gian - HTI thuộc Viện hàn lâm Khoa học và Công nghệ Việt Nam chế tạo đã bay thử nghiệm thành công 05 mẫu máy bay không người lái. Sự kiện này được thế giới đánh giá cao công nghệ của Việt Nam trong lî́nh vực nghiên cứu chế tạo máy bay không người lái tiếp tục mở ra bước đột phá mới trong phát triển các loại UAV phục vụ khoa học và các mục đích dân sự cũng như quốc phòng trong tương lai.

Các mẫu UAV đang được Viện Công nghệ không gian phát triển là AV.UAV.MS1, AV.UAV.S1, AV.UAV.S2, AV.UAV.S3, AV.UAV.S4 với bán kính hoạt động từ 2-100km, trần bay từ 200-3.000 mét, thời gian hoạt động từ 1-3 giờ.

Sáng ngày 25/5, Viện Công nghệ không gian - HTI thuộc Viện hàn lâm Khoa học và Công nghệ Việt Nam tiến hành bay chụp ảnh bãi biển huyện Vạn Ninh, Khánh Hòa, cách thành phố Nha Trang $100 \mathrm{~km}$ về phía Bắc trong chương trình bay phục vụ nghiên cứu khoa học biển trên vùng biển miền Trung

Trước đó, những chiếc máy bay không người lái của Viện Công nghệ không gian đã hoàn thành tốt bay thử nghiệm tại Tây Nguyên

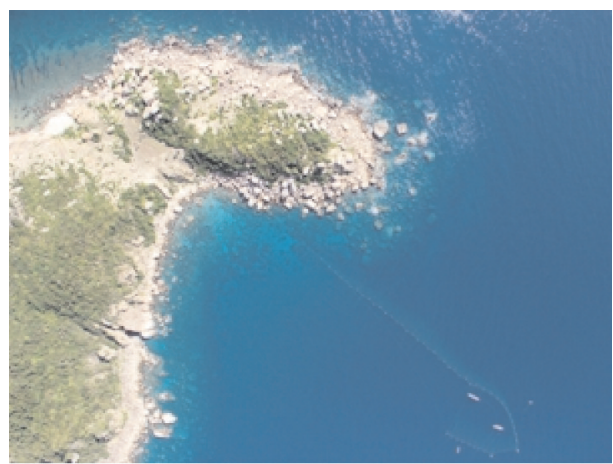
vào ngày 19/5. Theo đó, đợt bay kéo dài 3 ngày tại Tây Nguyên của 6 máy bay không người lái thực hiện tổng số 37 chuyến bay cho kết quả tốt, không có bất kỳ sai sót kỹ thuật nào xảy ra cho dù điều kiện bay ở Đà Lạt là rất phức tạp. 


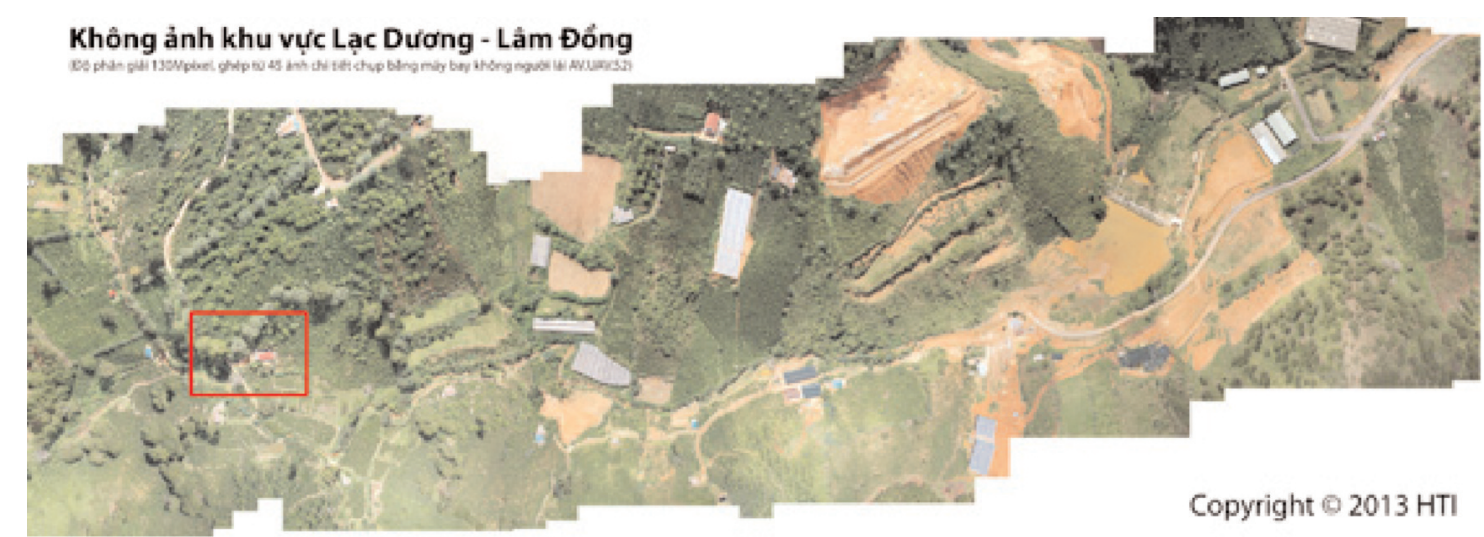

Nhằm nhanh chóng tiếp cận công nghệ UAV hàng không hiện đại của thế giới, Hiệp hội hàng không vũ trụ Việt Nam VASA đã hợp tác với công ty chế tạo máy bay Irkut của Nga để phát triển các UAV phục vụ cho mục đích dân sự. Chế tạo những chiếc UAV trinh sát đẳng cấp như Hermes-450 của Israel là tương lai không quá xa vời đối với Việt Nam.

\section{c. Kết quả thử nghiệm bay chụp ảnh bằng thiết bị MD4-1000}

Quá trình bay chụp ảnh được thực hiện cùng lúc với công tác đo đạc khống chế ảnh ngoại nghiệp bằng máy GPS 2 tần. Hệ tọa độ Quốc gia VN-2000, lưới chiếu UTM, múi chiếu $3^{0}$, kinh tuyến trục 1050, hệ độ cao Hòn Dấu - Hải Phòng. Công trình thử nghiệm đã được công bố trong [6].

- Thông số máy chụp ảnh, ảnh chụp và máy bay:

+ Tên máy chụp: Olympus EP

+ Tiêu cự: $\quad$ 17.090476mm

+ Cỡ ảnh (CCD): $17.7408 \times 13.3056$ mm

+ Kích thước pixel: $4.4 \mu \mathrm{m}$

+ Tọa độ điểm chính ảnh (PBS): $X=0.032982 \mathrm{~mm}, Y=-0.074 \mathrm{~mm}$

+ Tham số méo hình hướng tâm (radial distortion coeffients):

K1=1.679973E-4 K2=-3.286605E-7

+ Tham số méo hình tiếp tuyến (Tangential distortion coefficients):

$P 1=-3.124259 \mathrm{E}-5$ $P 2=5.29212 E-5$

+ Tên thiết bị bay: Microdrones MD4-1000

- Thông số bay chụp ảnh:

+ Độ cao chụp ảnh so với mặt đất: 100m.

+ Độ phủ dọc: $80 \%$.

+ Độ phủ ngang: $60 \%$.

+ Tỷ lệ chụp ảnh: 1/5800. 
- Tổng số ảnh bay chụp 160 ảnh.

- Chất lượng hình ảnh: Ảnh có độ nét cao, màu sắc trung thực, khả năng nhận dạng rất tốt. Tuy nhiên có một số ít ảnh hơi nhòe.

- Các file thông số bay chụp ảnh gồm tọa độ tâm ảnh, các góc xoay.

Kết quả tính tăng dày, đo vẽ

Toàn bộ các công đoạn tính toán tăng dày nội nghiệp, đo vẽ lập thể, tạo lập DTM, xử lý ảnh thành lập bình đồ trực ảnh được thực hiện trên phần mềm chuyên dụng của hãng Intergrap.

Kết quả tăng dày

- Tổng số ảnh được đo và tính toán 154 ảnh.

- Tổng số điểm khống chế tổng hợp 34 điểm, số điểm kiểm tra 3 điểm.

+ Sai số trung phương tại điểm khống chế ảnh sau bình sai:

$$
M x=0.041 \mathrm{~m} \quad M y=0.069 \mathrm{~m} \quad M h=0.052 \mathrm{~m}
$$

+ Sai số trung phương tại điểm kiểm tra.

$$
\mathrm{Mx}=0.046 \quad \mathrm{My}=0.059 \mathrm{~m} \quad \mathrm{Mh}=0.228 \mathrm{~m}
$$

d. Một số sản phẩm của công nghệ chụp ảnh hàng không từ hệ thống máy bay không người lái Microdrone MD4-1000
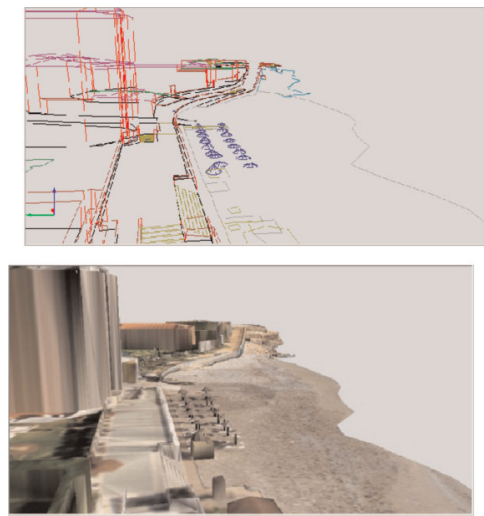

Bay chụp ảnh thành lập bản đồ 3D khu vực thành phố
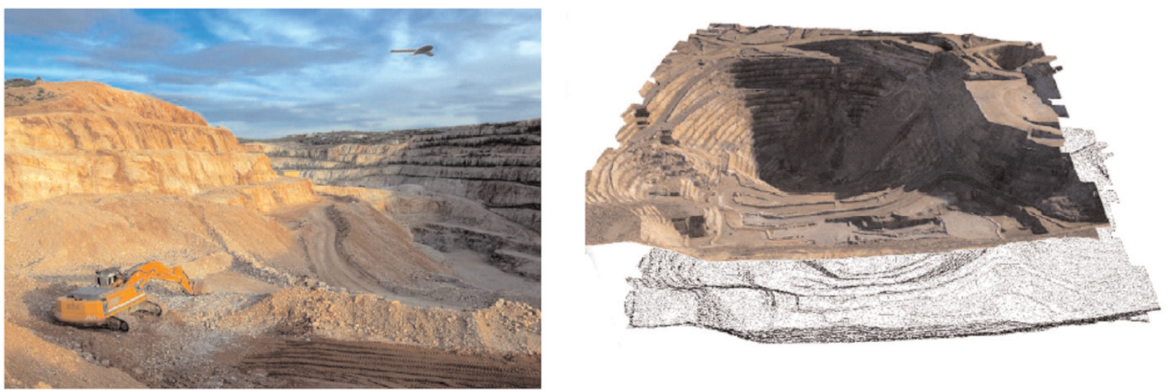

Bay chụp ảnh thành lập bản đồ 3D khu vực khai thác mỏ 
Một số công trình nghiên cứu của Phan Văn Lộc về ứng dụng máy chụp ảnh số phổ thông vào việc thành lập bản đồ tỷ lệ lớn ở mỏ lộ thiên [4], vào thành lập bản đồ địa hình tỷ lệ cực lớn [5],[6] đã khẳng định khả năng thực hiện của quy trình thành lập bản đồ địa hình tỷ lệ lớn và cực lớn ở nước ta.

\section{Kết luận}

Hệ thống thiết bị bị chụp ảnh số phổ thông đặt trên máy bay không người lái đã có cơ sở lý thuyết và thực nghiệm để thực thi quy trình công nghệ thành lập bản đồ địa hình tỷ lệ lớn và cực lớn. Đây là một hướng phát triển hứa hẹn mang lại sự tiện lợi, hiệu quả kinh tế cao, đáp ứng tốt nhịp độ phát triển tin học hóa, tự động hóa; có khả năng cạnh tranh cao phù hợp với yêu cầu của sản xuất ở nước ta hiện nay. $\bigcirc$

\section{Tài liệu tham khảo}

[1]. Trần Trung Anh, Phan Văn Lộc, 2004, Kiểm định máy chụp ảnh số phổ thông và khả năng ứng dụng trong thành lập bình đồ tỷ lệ lớn, Tạp chí KHKT Mỏ Địa chất số 8, 10/2004 tr 33-37, Hà Nội.

[2]. Trần Trung Anh, 2005, Công nghệ đo ảnh trên cơ sở ảnh chụp từ máy chụp ảnh số phổ thông, Luận văn Thạc sĩ kỹ thuật, Trường Đại học Mỏ Địa chất, Hà Nội.

[3]. Lê Văn Hường, 2000, Đo ảnh Mặt đất, Nhà xuất bản Giao thông Vận tải, Hà Nội.

[4]. Phan Văn Lộc, Trần Trung Anh và nnk, 2004, Chuyên đề "Ứng dụng chụp ảnh số phổ thông vào việc đo vẽ bản đồ địa hình và xác định khối lượng khai thác ở mỏ lộ thiên", Đề tài HTNC02 Việt Nam - Ba Lan, Hà Nội.

[5]. Lê Thị Sinh, 2008, Thử nghiệm thành lập bản đồ địa hình tỷ lệ lớn bằng ảnh hàng không chụp từ máy ảnh số phổ thông, Luận văn Thạc sĩ kỹ thuật. Trường Đại học Mỏ Địa chất, Hà Nội.

[6]. Lê Duy Hiếu, 2013, Nghiên cứu sử dụng tư liệu ảnh hàng không được chụp bằng máy bay không người lái để thành lập bản đồ, Luận văn Thạc sĩ kỹ thuật, Trường Đại học Mỏ Địa chất, Hà Nội.

[7]. Marcos Lopez (CARTOUAV) \& Michael Thoss (microdrones GmbH), 2012, Photogrammetry with the help of microdrones md4-1000.www.Microdrone.com. $\bigcirc$

\section{Summary}

Applicability of the Non-Metric camera laid on unmanned aircraft to build technology process of establishment large scale map in Viet Nam.

Prof. Dr. Sc. Phan Van Loc - Hanoi University of Mining and Geology

MSc. Nguyen Tuan Anh - Survey and Aerial Mapping One member limited liability company

This paper presents the applicability of aerial photography system from unmanned aircraft in the establishment large scale map. It's a new direction to develop the map establishment technology by aerial photogrammetric methods. $O$

Ngày nhận bài: 18/11/2013. 